\title{
Ciência e Arte: uso de filmes como proposta pedagógica para o ensino de infecções sexualmente transmissíveis (IST)
}

\author{
science and art: use of films as a pedagogical proposal for the teaching of \\ sexually transmitted infections (STIS)
ciencia y arte: uso de películas como propuesta pedagógica para la enseñanza de las infecciones de transmisión sexual (ITS)

\author{
Leonardo da Silva Cândido, (contatoleonardobraz@gmail.com) \\ Centro Universitário de Volta Redonda - UniFOA
}
Carlos Alberto Sanches Pereira, (contatoleonardobraz@gmail.com) Centro Universitário de Volta Redonda - UniFOA

Lucas Peres Guimarães, (lucaspegui@hotmail.com) Instituto de Educação Ciência e Tecnologia do Rio de Janeiro - IFRJ

Ana Paula Cunha Pereira, (ana.paula@foa.org.br) Centro Universitário de Volta Redonda - UniFOA

\begin{abstract}
Resumo: A utilização do audiovisual para mediar a aprendizagem nas aulas de Ciências Naturais tem crescido constantemente nas escolas. Os filmes possuem um potencial didático-pedagógico importante para os alunos, pois estes conseguem visualizar conflitos e se tornarem críticos. O HIV/AIDS é uma das IST's que na última década, seu índice de contágio mais que dobrou entre jovens de 15 a 19 anos. Considerando que nessa faixa etária a maioria dos jovens está no ensino médio, buscou-se criar uma proposta pedagógica com a criação de um filme com cenas fragmentadas das obras cinematográficas de filmes estes que abordaram a temática. Os fragmentos no filme foram organizados abordando epidemiologia e o contexto histórico da doença, o uso de drogas e a promiscuidade, a sintomatologia e a ética. O uso do cinema como fins pedagógicos contribuirá na aprendizagem do aluno de forma significativa, pois os filmes são capazes de contribuir na formação e organização prévia dos conceitos
\end{abstract}

Palavras-chave: Filmes; Ensino-Aprendizagem; IST's

Abstract: The use of audiovisuals to mediate learning in Natural Science classes has grown constantly in schools. The films have an important didactic-pedagogical potential for the students, because they can visualize conflicts and become critical. HIV/AIDS is one of the STI's that in the last decade, its rate of contagion has more than doubled among young people from 15 to 19 years old. Considering that in this age group most of the young people are in high school, a pedagogical proposal was created with the creation of a film with fragmented scenes from the cinematographic works of films that 
approached the subject. The fragments in the film were organized addressing epidemiology and the historical context of the disease, drug use and promiscuity, symptomatology and ethics. The use of cinema as pedagogical purposes will contribute in the learning of the student in a significant way, because the films are able to contribute in the formation and previous organization of the concepts

Keywords: Movies; Teaching-Learning; IST's

Resumén: El uso de medios audiovisuales para mediar el aprendizaje en las clases de Ciencias Naturales ha ido creciendo constantemente en las escuelas. Las películas tienen un importante potencial didáctico-pedagógico para los alumnos, ya que pueden visualizar los conflictos y ser críticos. El VIH/SIDA es una de las ITS que en la última década ha duplicado su tasa de infección entre los jóvenes de 15 a 19 años. Teniendo en cuenta que en esta franja de edad la mayoría de los jóvenes están en la escuela secundaria, buscamos crear una propuesta pedagógica con la creación de una película con escenas fragmentadas de las obras cinematográficas de estas películas que abordaban el tema. Los fragmentos de película se organizaron abordando la epidemiología y el contexto histórico de la enfermedad, el consumo de drogas y la promiscuidad, la sintomatología y la ética. El uso del cine con fines pedagógicos contribuirá al aprendizaje de los alumnos de manera significativa, ya que las películas son capaces de contribuir a la formación y organización previa de los conceptos

Palabras clave: Cine; Enseñanza-Aprendizaje; TSI

\section{INTRODUÇÃO}

O currículo de Biologia para o ensino médio, leva ao professor para cumprir um grande desafio de trabalhar com uma gama de conceitos, seres vivos, processos e mecanismos que muitas vezes se apresenta distante do interesse do educando (DURÉ et al., 2018). Observa-se que, a afinidade dos alunos da educação básica com a Biologia acontece a partir da aproximação do cotidiano/vivência, neste caso, ganha-se destaque temáticas sobre Zoologia, Reprodução, Saúde e doenças que passam ao longo do desenvolvimento escolar dos mesmos (ARAÚJO; SANTOS, 2014).

Uma das dificuldades encontradas pelos professores é abordagem a respeito de Educação Sexual, e dentro da grande quantidade de conceitos, destaca-se as infecções sexualmente transmissíveis ${ }^{1}$; especificamente a HIV/AIDS, que vem se tornando uma

1 O nome de Infecções Sexualmente Transmissíveis (IST) passou a ser adotada em substituição à expressão Doenças Sexualmente transmissíveis (DST), porque destaca a possibilidade de uma pessoa ter e transmitir uma infecção, mesmo sem sinais e sintomas. 
doença negligenciada no Brasil pois no decorrer dos anos houve grande índice de crescimento de pessoas infectadas.

Desde os Parâmetros Curriculares Nacionais (PCN), a discussão sobre HIV/AIDS na escola deve ser abordada; por se tratar de uma temática de prevenção de doenças, e a abordagem se dá por um eixo transversal, ou seja, essa temática precisa ser discutida em todas as disciplinas escolares (BRASIL, 1998). Esse trabalho sugere a utilização de filmes como um recurso pedagógico para a abordagem do tema.

Os filmes utilizados, anteriormente estavam nos cinemas, aparecem como entre outras expressões artísticas tais como a música e a literatura. Os filmes são capazes de "ampliar os horizontes" sobre o ensino de ciências. Desta forma, vem tomando vulto não somente como entretenimento, mas também como recurso pedagógico para o ensino nos espaços formais e não-formais, como potencial elemento educativo na medida em que a linguagem cinematográfica tem como princípio favorecer a identificação do aluno, relacionando a escola e a "cultura cotidiana" mais ampla (SILVA; BARROS; LA ROCQUE, 2017).

De acordo com Anjos, Pereira e Correia (2014), os filmes podem compor veículo divulgador da ciência em sala de aula, despertando paixões, enchendo o olhar de vontade criativa, de sensibilidade de realização. Os vídeos, nas suas imagens cinematográficas, ao serem empregados na esfera das ciências, agem como propulsores da imaginação, agem como observação minuciosa que tem na composição dos fragmentos a expressão do todo, de um modelo que pode apresentar a ciência.

O uso do filme em sala de aula visa oportunizar e facilitar a mediação de conteúdo, sendo assim um recurso didático a fim de complementar a aula realizada pelo professor. Os filmes possuem um dispositivo didático na interação ficção e realidade, importante para os alunos, pois estes conseguem visualizar seus próprios conflitos e se tornarem críticos; através da ludicidade.

De acordo com Barros, Girasole e Zanella (2013), quando o professor opta ao utilizar o cinema como estratégia para abordar um conteúdo, é importante que ele tenha os objetivos específicos que ele almeja alcançar utilizando este recurso em sua aula. Um 
exemplo disso é que os professores desenvolvam com seus alunos a capacidade de interpretação, juntamente com uma postura crítica aos conteúdos administrados, pois somente dessa forma os resultados esperados com a estratégia do uso de cinema serão alcançados.

O uso do cinema como estratégia didática em sala de aula possui grande valor pedagógico, quando são trabalhados em uma visão que promova nos alunos, esclarecimento de ideias do que estava superficial na mente; esta visão está diretamente ligada com a construção dos saberes e a formação dos aspectos cognitivos do pensamento (ANJOS; PEREIRA; CORREIA, 2014).

De acordo com o estudo desenvolvido por Barros, Girasole e Zanella (2013) com professores da educação básica, com intuito de incentivar os demais profissionais a utilizarem o cinema como estratégia didática, conclui-se que a utilização do cinema nas aulas deveria ser compreendida de uma maneira tão completa como todos os demais recursos didáticos já existentes.

Inúmeras pessoas desconhecem a relevância dos filmes no processo de ensino aprendizagem, que por meio deste, adquirem experiências e desenvolvem seu conceito sobre o mundo que as cercam, pois é por meio do lúdico que há o desenvolvimento de competências de aprender a ser, aprender a conviver (MODESTO; RUBIO, 2014)..

Diante desse contexto favorável para o uso do cinema no ensino formal, o espaço escolar é capaz de ser um ambiente favorável para consolidar estratégias de ensino estruturadas em sequências didáticas: planejamento, execução, sistematização e articulação de conceitos (MORTIMER; SCOTT, 2002). Sendo assim, não há dúvidas em relação ao papel das escolas atuais como ótimos locais para a divulgação do conhecimento científico, devido a oportunidades de se reunir alunos, professores e comunidade, "conectando ciência e cultura".

Diante do exposto, o presente trabalho teve como objetivo sistematizar cenas de filmes e utilizá-los como proposta pedagógica visando contextualizar a temática HIV/AIDS. Destaca-se que, tal sistematização lançou mão dos seguintes filmes: “Cazuza, o tempo não para", "Filadélfia", "Clube de Compra Dallas", e o clássico "E a vida continua"(And the Band Play On). Essa proposta pedagógica possui aderência 
junto aos professores do Ensino Médio, àqueles que lecionam especificamente no $3^{\circ}$ ano. Por fim, a aproximação dos discentes da referida temática e o foco na reflexão crítica inserindo-os em debates que tangem os Direitos Humanos, a Ética, a Ciência e a Cidadania são parte deste processo de ensino.

\section{DESENVOLVIMENTO E CONSTRUÇÃO DA PROPOSTA}

Para estruturação desta proposta pedagógica, foi realizado um levantamento das principais IST que possuem maior taxa de incidência no Brasil, utilizando o DATASUS, site de dados estatísticos do Sistema Único de Saúde (SUS) e o boletim epidemiológico do Ministério da Saúde.

Após a realização da análise dos levantamentos, concluiu-se que a maior taxa de incidência é o HIV/AIDS, principalmente em adolescentes e jovens em idade escolar. Partiu-se deste ponto para pesquisar a respeito do Ensino de Biologia no Ensino Médio e pensar em uma estratégia didática de como abordar HIV/AIDS de forma significativa. O caminho metodológico desenvolvido ao longo do trabalho, baseou-se na literatura e em artigos científicos (BREMM, 2019; ANJOS; PEREIRA; CORREIA, 2014; MODESTO; RUBIO, 2014). Neste sentido, considerando que, a utilização de filmes "possibilitam diálogo e sistematização durante o seu desenvolvimento, uma vez que permitem inserção de perguntas mediadora pelo professor, o que favorece muito a aprendizagem" (BREMM, 2019, p. 93).

Para isso realizou-se uma investigação por obras cinematográficas cuja abordagem temática foi HIV/AIDS. Ao identificarmos a variedade de filmes existentes, notamos a necessidade de realizarmos uma triagem destes materiais. A seleção foi realizada com base nas seguintes categorias temáticas:

- abordagem do contexto histórico,

- processo de contágio,

- sintomatologia e ética.

As obras selecionadas para composição do curta-metragem foram:

- E a Vida Continua (And the Band Played On) (1993), 
- Filadélfia (1993),

- Cazuza - O tempo não para (2004)

- Clube de Compra Dallas (2013).

"E a Vida Continua" (And the Band Played On), é um filme americano que foi produzido em 1993, categorizado como drama. Baseado no livro de Randy Shilts o mesmo retrata os primeiros anos da AIDS nos Estados Unidos, desde o início das mortes em São Francisco, até o descobrimento do vírus HIV.

"Filadélfia", é um filme norte-americano que foi produzido em 1993, categorizado como drama. É um dos primeiros filmes comerciais de Hollywood para reconhecer HIV/AIDS, homossexualidade e homofobia. O filme conta a história de um advogado homossexual que trabalha em uma prestigiosa firma em Filadélfia. Quando fica impossível para ele esconder dos colegas de trabalho o fato de que tem AIDS, é demitido.

“Cazuza - O tempo não para", é um filme brasileiro que foi produzido em 2004, categorizado como drama biográfico. Baseado no livro "Cazuza, Só As Mães São Felizes”, escrito pela mãe do cantor. O filme conta a história do cantor brasileiro, sua vida regrada ao consumo de álcool, drogas e promiscuidade.

Clube de Compras Dallas”, é um filme americano que foi produzido em 2013, categorizado como drama. O filme retrata sobre um eletricista heterossexual que é diagnosticado com AIDS e que passa contrabandear medicamentos alternativos não aprovados pela FDA dentro dos Texas, distribuindo-os para outros pacientes e estabelecendo, assim, o "Clube de Compras Dallas".

Posteriormente será feita uma análise de cada filme, recortes de cenas e a construção de um vídeo para ser utilizado em contextos educativos a partir das montagens com as cenas selecionadas de cada filme. As informações dos filmes mencionados nesse artigo foram devidamente retiradas do site Filmow ${ }^{2}$, site onde hospeda a ficha técnica de inúmeras obras cinematográficas.

${ }^{2}$ https://filmow.com/ Acesso em 24 de out de 2020 
Para a construção do filme a ser utilizado na sala de aula, utilizou-se o programa Windows Movie Maker, visando promover o recorte e a edição das cenas selecionadas. As cenas foram organizadas em categorias temáticas, e antecedendo cada cena selecionada do filme elaboramos uma descrição do tema a ser abordado. Ao final da exibição de cada cena, aparece uma tela com duas questões sugestivas a respeito da cena assistida a fim de instigar o nível de percepção dos alunos.

\section{APLICABILIDADE DA PROPOSTA}

O Ensino de Biologia deve reconhecer a real possibilidade de compreender o conhecimento científico e sua relevância na formação dos alunos, uma vez que essa mesma disciplina colabora para ampliação da capacidade de compreensão e atuação da sociedade a qual estamos inseridos (ROCHA et al., 2012).

Procurou-se direcionar esta pesquisa de forma que possa adota-la como proposta pedagógica, em que o professor se torna o mediador e possibilitará aos alunos reflexões acerca da temática, no que está contido nos livros e nas demais fontes de informação; relacionando assim com à leitura das imagens reveladas pelo audiovisual. Sendo assim, ao associar o aprendizado científico com o aprendizado cinematográfico, será possível que os alunos criem uma visão crítica e, ainda, contextualizada da sociedade em que vivem.

O aluno ao assistir o longa-metragem com as cenas selecionadas, será capaz de correlacionar o que está se passando em cena com o conhecimento teórico abordado em sala de aula. A figura 1 representa quatro situações reproduzidas durante o filme, momento do contexto histórico da doença (figura A), ética (figura B), contágio (figura C), sintomatologia e processo de adoecimento (figura D); pontos esses que podem ser visualizados no filme e discutidos em sala de aula.

Figura 1 - Cenas selecionadas na proposta 


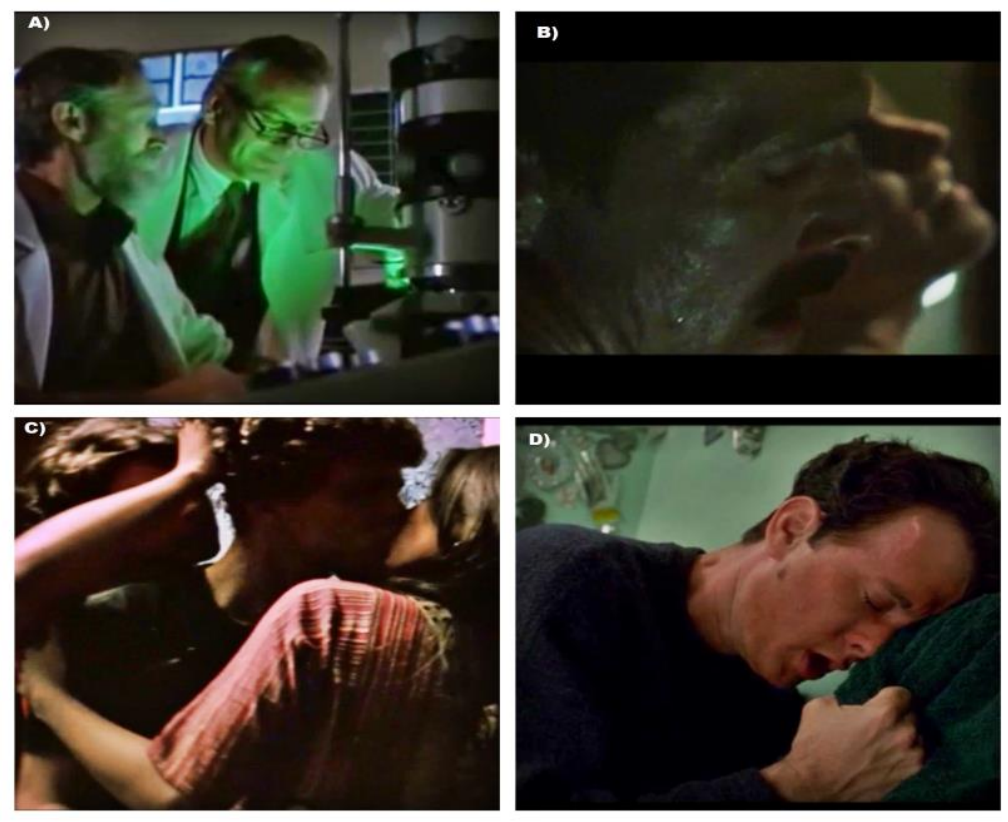

Fonte: O Autor.

A figura A representa a primeira obra cinematográfica que compõem o filme, " $\mathrm{E}$ a vida continua" de 1993, essa obra foi selecionada para narrar o contexto histórico da Síndrome da Imunodeficiência Humana. Das cenas que foram fragmentadas para construção deste filme educativo pode-se extrair alguns pontos para serem discutidos em sala. O primeiro ponto a ser discutido é sobre epidemia, com o aparecimento de uma nova doença que aparentemente infectava apenas pessoas que mantinham práticas homossexuais, por este motivo a doença por muito tempo conhecida como "câncer gay" e "peste gay", com isso pode-se analisar que durante toda o processo de pesquisa da doença houve discriminação e preconceito com pessoas homossexuais. O Segundo ponto a ser discutido é sobre o isolamento do vírus e o início da disputa entre os médicos norte-americanos e franceses pela autoria da descoberta da doença.

A figura B representa o filme "Clube de Compras Dallas" de 2013, que foi selecionado para narrar a categoria temática sobre ética; o filme discute sobre um eletricista heterossexual que foi diagnosticado com AIDS, após receber o diagnóstico inicia-se no contrabando de medicamentos alternativos não autorizados Food and Drug Administration (FDA).

Destaca-se que, o comércio destes fármacos é ilegal, embora o personagem tenha ignorado a ética, visando desta forma, apenas no lucro, podendo colocar em riscos 
a vida das pessoas que consumiam tais fármacos. É necessário levar em consideração que o tratamento com o AZT deve ser prescrito por um médico e que existe todo um processo de burocratização para conseguir os medicamentos.

A figura C apresenta o filme "Cazuza - o tempo não para", não obstante o objetivo deste filme seja narrar a biografia do ícone do rock brasileiro, pode-se extrair pontos chaves para aprendizagem de ensino HIV/AIDS. Ao assistir ao filme, analisa-se que, Cazuza teve sua vida boêmia regada a utilização de drogas, que por consequência deixa o sistema imunológico da pessoa frágil e susceptível a contrair doenças; observase que, Cazuza, era bissexual assumido e possuía diversos parceiros sexuais, tornando assim uma pessoa promiscua; o sexo desprotegido é um dos fatores que podem levar ao contágio do HIV ou qualquer outra IST.

A figura D representa o filme "Filadélfia", essa obra foi selecionada afim de discutir a sintomatologia. Pode-se extrair dois pontos para aprendizagem de HIV/AIDS, o primeiro ponto é o aspecto sintomatológico; cujo Andrew começa ter mal-estar e descobre que sua imunidade está muito baixa, logo em seguida, feridas vão surgindo em seu corpo. O segundo ponto é o processo de adoecimento onde o ator desenvolve a AIDS, e os aspectos fisionômicos são nítidos neste momento.

A utilização do cinema como proposta pedagógica nas aulas de Ciências e Biologia, pode trazer vários benefícios para os alunos, quanto para os professores em seu exercício profissional. Algum destes benefícios são: tornar a aula mais lúdica, melhor assimilação do conteúdo científico e o cinematográfico, criar um pensamento mais crítico e a melhor compreensão das temáticas abordadas em sala de aula (PRADO, 2010).

Isto significa dizer que, o cinema pode contribuir como uma proposta pedagógica relevante no processo de ensino aprendizagem. Para Coelho e Viana (2011), educar com o cinema é ensinar a lançar um olhar diferente, ou ainda, é educar com o olhar. Dessa forma, o cinema pode ampliar a visão da educação e auxiliar na forma diferente de ensinar.

Segundo Napolitano (2009 p.11), o cinema como um caminho pedagógico em sala de aula "é ajudar a escola a reencontrar a cultura ao mesmo tempo cotidiana e 
elevada, pois o cinema é o campo no qual a estética, o lazer, a ideologia e os valores sociais mais amplos são sintetizados numa mesma obra de arte." É fato que o cinema auxilia em diversos aspectos no processo ensino-aprendizagem, todavia o professor que opta ao utilizar essa proposta pedagógica deve adicionar uma leitura mais ampla acerca da temática visando a aquisição da distinção por parte do aluno em relação ao conhecimento científico do cinematográfico (CAVALCANTE, GASTAL,2018). Para isso, "a contextualização é fundamental, pois oferece um espaço de participação para o aluno, instigando o compartilhamento das ideias advindas do conhecimento prévio sobre o fenômeno proposto" (DE LUCA et. al., 2018, p. 2)

Ressalta-se que, a utilização do cinema em sala de aula, nunca deverá substituir uma aula convencional, essa metodologia é um auxílio para tornar as aulas mais dinâmicas e menos exaustiva para os alunos e professores. De acordo com Napolitano (2003), as crianças aprendem ao ver imagens em movimento, assim compreendendo as convenções narrativas e podendo prever possíveis desenvolvimentos na história, isso é bom nos primeiros contatos com textos escritos. O estímulo e o interesse da criança provocados pelo filme pode incentivar a criança a ler textos mais complexos. Porém, isto também é uma verdade aplicável em jovens e adultos, o professor que optar por utilizar o cinema em sala de aula, terá que descobrir nos filmes o processo de escolarização, e retirar deles reflexos que levem os alunos desenvolvam no aluno o raciocínio mais profundo acerca da temática do filme, aí está o ponto chave da utilização de filmes em sala de aula (COELHO E VIANA, 2011).

Usar os filmes em sala de aula é uma excelente estratégia didática, pois o aluno se torna mais interessado, pelo fato de a aula ser tornar diferenciada e sair do método convencional, mas sempre relacionado ao conteúdo programático determinado no currículo da disciplina.

No ponto de vista educacional, entendemos a importância da utilização do audiovisual como recurso metodológico em sala de aula, visto que na prática educativa o cinema oportuniza melhores condições de aprendizagem de forma didática, tornandose assim as aulas em atividades significativas. 


\section{CONSIIDERAÇÕES FINAIS}

O filme como proposta pedagógica no processo ensino-aprendizagem nos conduziu a possibilidade de formular perguntas compatíveis com temáticas que envolve o processo de educação de modo geral. No caso da nossa experiência combinando Arte e Ciência observamos a uma modificação no espaço em sala de aula que chamamos aqui de transformação de paradigma ao dialogarmos com campos diferenciados do conhecimento. Destacamos que, no campo da História, indubitavelmente as interfaces entre Arte e Ciência é novidade e como exemplo temos à obra de Leonardo da Vinci.

A aproximação destes campos do conhecimento nesta proposta tangencia temáticas de aspectos históricos, culturais, literários, políticos e científicos, proporcionando desse modo uma visão integral do cinema como recurso de mídia educativa; ainda que não categorizados como dispositivos não formais no ensino de ciências.

A proposta de utilização do filme durante a aula de Biologia visou buscar a melhoria no processo de aprendizagem sobre HIV/AIDS. O aluno quando assistir ao filme deverá ser capaz de realizar assimilação do conteúdo teórico/científico com o conteúdo cinematográfico, desenvoltura do pensamento crítico para compreender que a ciência não é estática, reflexão e esclarecimento de possíveis dúvidas.

Sendo assim espera-se que com a utilização do filme o processo de aprendizagem seja significativo, ancorando-se com os conhecimentos prévios que o aluno já possui das aulas teóricas sobre HIV/AIDS com o novo conhecimento adquirido através do filme exposto, deste modo, a partir de um conceito geral o conhecimento pode ser construído de modo a liga-lo com novos conceitos facilitando a compreensão de novas informações, o que dará significado ao conhecimento adquirido. 


\section{REFERÊNCIAS}

ANJOS, M. B; PEREIRA, M, V; CORREIA, K. Cinema, Arte e Educação: confluências no ensino de ciências. 1 ed. Rio de Janeiro: Publit Soluções Editoriais, 2014.

ARAÚJO, A, A, C; SANTOS, S, P. Olhares para o ensino em biologia: concepções de estudantes do ensino médio. In: ENCONTRO NACIONAL DE DIDÁTICA E PRÁTICAS DE ENSINO, 14, 2014, Ceará, Anais... Curitiba, 2014.

BALBINOT, E, M; MIQUELIN, C, A. O cinema como agente: educação e aprendizagem por narrativas de epidemias. In: SEMINÁRIO NACIONAL CINEMA EM PERSPECTIVA, 2, 2013, Curitiba, Anais... Curitiba, 2013.

BARROS, M, D, M; GIRASOLE, M; ZANELLA, P, G. O uso do cinema como estratégia pedagógica para o ensino de ciências e de biologia: o que pensam alguns professores da região metropolitana de Belo Horizonte. Práxis, n.10, p. 97-115, 2013.

BASTOS, W. G. et al. A questão do reendereçamento na recepção audiovisual em uma aula de biologia. In: XI ENPEC, 11, 2017, Florianópolis, Anais... Florianópolis, 2017.

BRASIL. Parâmetros Curriculares Nacionais: Ciências naturais: Ensino de primeira à quarta série. Brasília: MEC/SEF, 1997. 136p.

BREMM, D. Os filmes e jogos didáticos no trabalho educativo com reeducação alimentar. Revista Insignare Scientia - RIS, v. 2, n. 3, p. 92-102, 21 nov. 2019. DOI: https://doi.org/10.36661/2595-4520.2019v2i3.11186

CAVAlCANTE, E, C, B; GASTAL, M, L, A. Ensino de Biologia na Educação Prisional e a exibição de documentário, filme de curta e longa metragem. In: ENCONTRO NACIONAL EM EDUCAÇÃO EM CIÊNCIAS, 8, 2018, Campinas, Anais... Campinas, 2018. 
COELHO, Roseana M. F. VIANA, Marger da C. V. A utilização de filmes em sala de aula: um breve estudo no instituto de ciências exatas e biológicas da UFOP. Revista da Educação Matemática da UFOP, v. I, p. 89-97, 2011.

DE LUCA, A. G., et.al. Experimentação contextualizada interdisciplinar: proposta para o ensino de ciências. Revista Insignare Scientia - RIS, v. 1, n. 2, Mai/Ago. p. 1-21, 2018. DOI: https://doi.org/10.36661/2595-4520.2018v1i2.7820

DURÉ, R, C; ANDRADE, M, J, D; ABÍLIO, F, J, P. Ensino de Biologia e contextualização do conteúdo: Quais temas o aluno do ensino médio se relaciona com seu cotidiano? Experiências em Ensino de Ciências, v. 13, n. 1, p. 259-272, 2018.

MODESTO, M, C; RUBIO, J, A, S. A importância da ludicidade na construção do conhecimento. Saberes da Educação. Disponível em < http://facsaoroque.br/revistaeletronica/revista-sabares-da-educacao/arquivos/2014-2/>. Acesso em: 17 de set. 2018.

MORTIMER, E. F.; SCOTT, P. Atividade discursiva nas salas de aula de Ciências: uma ferramenta sociocultural para analisar e planejar o ensino. Investigações em Ensino de Ciências, v. 7, n. 3, p. 283-306, 2002.

NAPOLITANO, M. Como usar o cinema em sala de aula. 4ed. São Paulo: Contexto, 2009.

NASCIMENTO, R, C. et al. Utilização de filmes comerciais no ensino de ciências. In: ENCONTRO REGIONAL SUL DE ENSINO DE BIOLOGIA, 6, 2013, Rio Grande do Sul. Anais... Rio Grande do Sul, 2013.

PRADO, L, F S. Cinema como proposta educativa. In: ENCONTRO DE PESQUISA EM EDUCAÇÃO DE ALAGOAS, 5, 2014, Alagoas, Anais... Alagoas, 2014.

ROCHA, L, B; SILVA, R, P; LIRA, L, T, O. Percepção dos educandos de uma escola pública estadual do Recife - PE sobre o ensino de ciências e biologia. Disponível em: http://www.fundaj.gov.br/images/stories/epepe/III_EPEPE/posteres_curriculo_ensi_aprend/perc epcao_dos_educandos.pdf $>$. Acesso em: 17 de set. 2018.

SETTON, M, G, J. A cultura da mídia na escola: ensaios sobre cinema e educação. São Paulo: Annablume: Usp, 2004

SILVA, M.M.; BARROS, M.D.M. \& DE LA ROCQUE, L.R. As questões sociocientíficas na trama do filme Elysium: conexões entre ciência e cidadania no "chão da escola". Revista Demetra, v.12, n.3. 2017.

TEIXEIRA, L. C. C.; DE LA ROCQUE, L, R. É preciso refletir sobre epidemia o filme contágio e sua aplicação ao ensino informal da ciência e da saúde. In: ENCONTRO DE CIÊNCIAS DA SAÚDE E DO AMBIENTE, 5, 2018, Niterói, Anais... Niterói, 2018. 